\title{
Identificação e destinação dos resíduos gerados pela produção de suínos em Palmitinho (RS)
}

\begin{tabular}{ll}
\hline Nadir de Jesus & $\begin{array}{l}\text { Universidade Estadual do Rio Grande do Sul (UERGS). Curso de Pós- } \\
\text { graduação em Liderança e Sustentabilidade. Unidade Universitária em } \\
\text { Frederico Westphalen. RS. Brasil. }\end{array}$ \\
$\begin{array}{l}\text { Zenicléia Angelita Deggerone } \\
\text { Jane Francisca Richter da Costa }\end{array}$ & $\begin{array}{l}\text { Universidade Estadual do Rio Grande do Sul (UERGS). Unidade } \\
\text { Universitária em Erechim. RS. Brasil. }\end{array}$ \\
E-mails: zenicleia-deggerone@uergs.edu.br & richter jane@yahoo.com.brem \\
\hline
\end{tabular}

Recebido em: 26 jan. 2018. Aceito: 01 maio 2018.

DOI: http://dx.doi.org/10.21674/2448-0479.43.432-446

\section{Resumo}

Este artigo tem por objetivo identificar os resíduos gerados pelos sistemas de produção de suínos desenvolvidos em propriedades rurais localizadas no município de Palmitinho (RS), e verificar como é realizada a destinação final desses resíduos. Para a realização do estudo, foi utilizado o método descritivo e exploratório, que contou com técnicas quantitativas e qualitativas para a coleta das informações. A pesquisa foi realizada em 10 propriedades rurais no município de Palmitinho (RS), entre os meses de dezembro de 2016 a janeiro de 2017. Por meio da realização deste estudo, foi possível caracterizar os sistemas de criação empregados pelos suinocultores, além da identificação dos distintos tipos de resíduos gerados pela atividade suinícola e também foram elencadas as formas de disposição final, utilizadas pelas unidades de produção. Concluiu-se que um dos principais sistemas de produção adotado pelos produtores pesquisados é o sistema de recria e terminação, realizado de modo confinado de forma integrada com as agroindústrias e que são produzidos efluentes líquidos, gasosos e resíduos sólidos durante o processo de produção. Os dejetos orgânicos líquidos da suinocultura são armazenados em esterqueiras, e posteriormente são aplicados nos cultivos de milho e pastagens forrageiras. Um dos pontos limitantes identificados pelo estudo se refere à inexistência de esterqueiras cobertas ou biodigestores para o adequado tratamento dos dejetos. Destaca-se também, que a gestão correta dos resíduos gerados pela atividade suinícola pode representar um diferencial na cadeia produtiva, além de manter o equilíbrio entre o processo produtivo e o ambiente.

Palavras-chave: Atividade suinícola. Dejetos suínos. Classificação dos resíduos. 


\section{Abstract \\ Identification and destination of waste residues generated by the production of pigs in Palmitinho (RS).}

This article aims to identify residues generated by pig production systems in rural properties located in the municipality of Palmitinho (RS) and to verify how waste final destination is being carried out. The present study used a descriptive and exploratory method including qualitative and quantitative techniques for the collection of information. Research was carried out in 10 rural properties in the municipality of Palmitinho (RS) between December 2016 and January 2017. By means of this study it was possible to characterize the type of breeding systems used by swine farmers, besides the identification of the different types of residues generated by the swine activity and also the final disposal methods used by the production units were also chosen. It was concluded that one of the main production systems adopted by swine producers is the post-weaning and termination system, carried out in an integrated manner with the agroindustry's and that liquid, gaseous and solid types of waste is produced during the production process. Liquid organic waste from swines is stored in mortars and later applied to maize and forage pastures. One of the limiting points identified by the study is the lack of indoor masks or biodigesters for the proper treatment of waste. Our results also emphasized that the correct management of residues generated by the swine activity may represent a differential in the productive chain besides maintaining the balance between the productive process and the environment.

Keywords: Activity pigs. Swine activity. Waste Classification.

\section{Introdução}

A suinocultura é umas das principais atividades agropecuárias desenvolvidas na Região Noroeste do Estado do Rio Grande do Sul. Essa atividade ocupa lugar de destaque na matriz produtiva da agropecuária, devido a grande capacidade de geração de renda em pequenas unidades de produção. De acordo com dados do último censo agropecuário (IBGE, 2006a), a criação de suínos aparece como o segundo maior rebanho do Estado com mais de 5 milhões de cabeças.

O município de Palmitinho, local onde foi desenvolvida esta pesquisa, está localizado na Região Noroeste do Estado do Rio Grande do Sul e se destaca na atividade suinícola por ocupar o primeiro lugar na produção de suínos com um número aproximado de 211.379 cabeças (ASSOCIAÇÃO DOS SUINOCULTORES DO ESTADO DO RIO GRANDE DO SUL, 2017).

Entretanto, o desenvolvimento desta atividade, em alguns casos pode tornar-se fonte de contaminação ambiental, como alerta Campos et al., (2014), pois segundo o autor, a atividade pode causar desequilíbrios químicos, físicos e biológicos ao solo, poluição das águas superficiais e 
subterrâneas, além de perdas de produtividade e redução da diversidade de plantas e organismos do solo. O sistema intensivo de produção, que se caracteriza por uma alta concentração de animais em pequenas áreas produtivas, o que ocasiona um elevado volume de resíduos tanto líquidos quanto sólidos.

Como salientado anteriormente, a produção de suínos tem grande importância econômica, social e ambiental para a região e especialmente para o município de Palmitinho, dessa forma o objetivo geral desse artigo é identificar os resíduos gerados pelos sistemas de produção de suínos, desenvolvidos em propriedades rurais no município de Palmitinho (RS) e verificar qual a destinação final destes resíduos.

A partir da criação da Lei 6.938/81 que dispõe sobre a Política Nacional do Meio Ambiente, houve a necessidade de adaptar os sistemas de produção agropecuários a fim de evitar possíveis danos causados por atividades potencialmente poluidoras, como o caso da suinocultura (BRASIL, 1981). Uma dessas adaptações diz respeito ao tratamento dos dejetos oriundos da atividade que, como observado por Barichello et al. (2015) pode causar sérios danos ao meio ambiente.

\footnotetext{
É necessário evitar que um volume tão grande de dejetos continue a ser lançado no meio ambiente, poluindo mananciais, solo, ar, pois comprometem não somente a qualidade de vida das populações rurais e urbanas, como também a sobrevivência da fauna e da flora das regiões onde os criatórios estão inseridos (BARICHELLO et al., 2015. p.335).
}

Dentro deste contexto, algumas pesquisas têm demonstrado a possibilidade da utilização destes resíduos para adubação de algumas culturas ou produção de gás. Uma das formas encontradas para a utilização destes resíduos é o seu aproveitamento, nas propriedades rurais, para adubação o que pode trazer benefícios, tais como: fonte de nutrientes para as plantas, incremento de matéria orgânica para o solo (BERTOL et al., 2010), melhoria das propriedades químicas e físicas do solo e redução do uso de fertilizantes químicos (VIELMO et al., 2011).

Cardoso, Oyamada, Silva (2015) destacam que na criação intensiva, os suínos são criados em confinamento dentro de baias ou gaiolas e em terrenos relativamente pequenos, considerando o tamanho da instalação utilizada para a produção dos animais. Este modelo de produção pode ser ainda subdividido em três tipos: (a) criação ao ar livre - em que os animais ficam dentro de piquetes; (b) criação tradicional - em que se utilizam os piquetes apenas para os machos e cobertura ou gestação para as fêmeas e (c) criação em confinamento - em que os animais permanecem sobre um piso e debaixo de uma cobertura, podendo-se subdividi-los por fases do ciclo de vida em várias instalações produtivas.

No Brasil e principalmente na Região Sul do País, são desenvolvidos sistemas intensivos de criação de suínos, que originam grandes quantidades de dejetos, os quais necessitam de destinação e tratamento. Os dejetos de suínos descartados de maneira incorreta ou sem nenhum tratamento poderão provocar impactos negativos sobre o ambiente, devido ao seu alto potencial poluidor. De acordo com Beli, Hussar, Hussar (2010) o potencial poluidor dos dejetos suínos reside na grande 
quantidade de matéria orgânica contida elevando substancialmente a exigência de DBO (Demanda Bioquímica de Oxigênio) do meio. Campos (2014) salienta que a destinação desordenada dos resíduos gerados pela atividade suinícola pode causar desequilíbrios químicos, físicos e biológicos ao solo, poluição das águas superficiais e subterrâneas, além de perdas de produtividade e redução da diversidade de plantas e organismos do solo.

\section{Materiais e Métodos}

O procedimento metodológico utilizado neste trabalho consiste em uma abordagem descritiva e exploratória. O modo de investigação escolhido foi a realização de estudos de casos múltiplos, que buscou identificar os resíduos gerados pela atividade suinícola em 10 unidades de produção, e o destino adotado pelos suinocultores para estes resíduos. Em relação ao número de unidades de produção utilizadas nesta pesquisa, salienta-se que inicialmente foram selecionadas 30 unidades produtoras de suínos para participar da pesquisa, porém, apenas 10 propriedades rurais aceitaram colaborar com a pesquisa.

A técnica de pesquisa utilizada caracteriza-se pelos métodos quantitativos e qualitativos. Para isso, foi utilizado um questionário orientador em 10 unidades de produção que desenvolvem sistemas de produção de suínos, localizados no município de Palmitinho (RS). Os dados foram coletados junto às propriedades rurais entre os meses de dezembro de 2016 a janeiro de 2017.

Salienta-se que este trabalho não foi encaminhado para a avaliação do comitê de ética, pois o questionário utilizado para a coleta das informações, buscou apenas quantificar informações técnicas dos sistemas de produção de suínos, conforme roteiro de perguntas disponíveis no apêndice A do artigo.

\section{Resultados e Discussões}

A área de estudo do trabalho foi o município de Palmitinho (RS), localizado na região noroeste do Estado, como pode ser observado na figura 1. Este município possui cerca de 7 mil habitantes e uma área total de $144,046 \mathrm{~km}^{2}$. A sua economia é baseada na agricultura, comércio, prestação de serviços e, principalmente, em atividades agropecuárias, como a bovinocultura leiteira e a produção de suínos. 


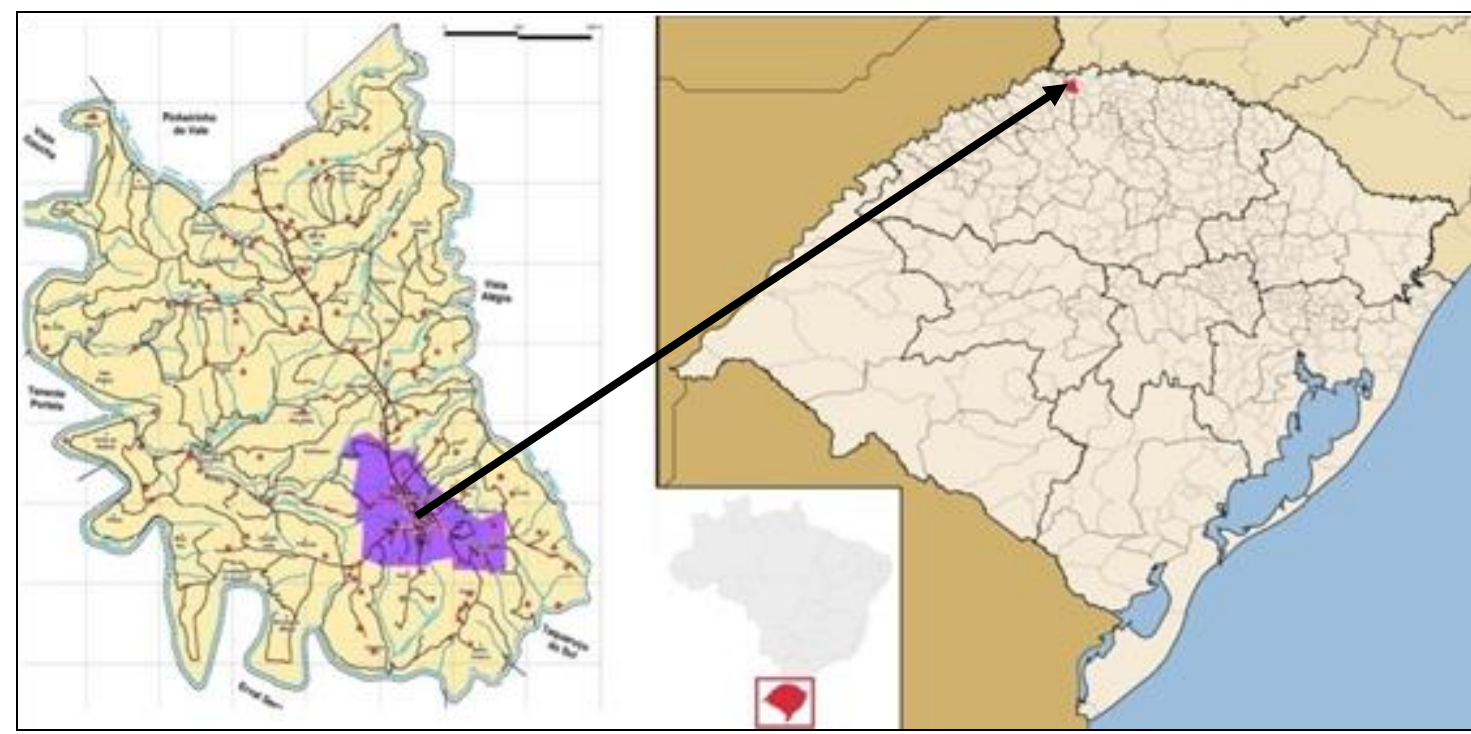

Figura 1 - Localização do município de Palmitinho/RS - área de estudo. Fonte: Adaptado de Bertê et al., (2016).

Segundo dados do último censo agropecuário do IBGE (2006b), Palmitinho tem um total de 948 estabelecimentos agropecuários envolvidos na criação de suínos. No entanto, como a pesquisa do IBGE não especifica o tipo de criação, comercial ou de subsistência e, tendo em vista que o presente trabalho baseou-se em pesquisa feita com produtores de suínos comerciais, não é possível afirmar a significância da amostra no município.

A atividade suinícola é desenvolvida nos sistemas extensivos e intensivos. No sistema extensivo os suínos geralmente são criados a campo, soltos, demandando uma área maior para acomodação dos animais. Já no sistema intensivo, os animais são agrupados em pequenas áreas, com cuidados mais intensivos, principalmente com manejo e alimentação.

Dessa forma, Campos (2014) destaca que essa subdivisão é organizada da seguinte forma: produção de ciclo completo; unidade de produção de leitões; unidade de terminação ou terminação, e a produção de reprodutores.

Cardoso, Oyamada, Silva (2015) destacam que os produtores de suínos podem optar por um modelo produtivo que englobe todo o ciclo de produção ou apenas uma fase. A produção de ciclo completo abrange todas as fases do ciclo de vida dos suínos, do nascimento ao abate, em uma mesma unidade de produção suinícola. A produção de leitões envolve apenas a fase de reprodução, ou seja, inseminação, gestação, parição e criação dos animais até o desmame (quando têm em média de 21 a 42 dias de vida ou de 6 a $10 \mathrm{~kg}$ ), ou até a saída da creche, que são os leitões enviados ao sistema de terminação (possuem em média de 50 a 70 dias de vida ou de 18 a $25 \mathrm{~kg}$ ). As unidades de terminação envolvem somente a fase de terminação. Estas unidades recebem os leitões das UPL, os conduzindo para terminação e tendo por produto final o suíno terminado destinado ao abate (SOBESTIANSKY et al., 1998). A produção de reprodutores visa a obtenção de reprodutores machos (varões para a produção de sêmen) e fêmeas (matrizes). 
A caracterização dos sistemas de produção de suínos identificados pela pesquisa, descritos na Tabela 1, revela que o sistema mais desenvolvido é o tipo recria/terminação, em sete unidades produtoras. Este tipo de criação se caracteriza como um sistema que envolve apenas a fase de criação e engorda dos animais. Também foi constatada, com menor expressividade, a existência da prática do sistema de ciclo completo, sendo desenvolvida em uma única propriedade rural, assim como os sistemas de que envolvem a Unidade Produtora de Leitões (UPL) 21 dias e a unidade produtora de matrizes que foram observadas em apenas uma propriedade cada.

O sistema de produção desenvolvido nas unidades produtoras pesquisadas é do tipo em confinamento, sendo que dos 10 suinocultores entrevistados, nove trabalham sob a forma de regime integrado de produção, em que as agroindústrias fornecem ração, animais, medicamentos, assistência técnica e, posteriormente fazem a aquisição dos animais para abate. Sob este sistema, o suinocultor, deve se responsabilizar com os investimentos e a manutenção das instalações, a mão de obra e as despesas com energia elétrica, água e o manejo dos dejetos.

Apenas um suinocultor entrevistado trabalha de forma independente na produção de suínos. Em relação a este sistema, o produtor deve dispor de capital de giro necessário para a aquisição de ração, os leitões e as matrizes, além de buscar formas para comercializar a produção de suínos para as agroindústrias processadoras.

Tabela 1 - Caracterização das unidades produtoras de suínos pesquisadas em Palmitinho (RS)

\begin{tabular}{cccc}
\hline $\begin{array}{c}\text { Unidade de } \\
\text { produção }\end{array}$ & Tipo de criação & $\begin{array}{c}\text { Modalidade de produ- } \\
\text { ção }\end{array}$ & $\begin{array}{c}\text { Número de } \\
\text { animais }\end{array}$ \\
\hline 1 & Ciclo Completo & Independente & 10.100 \\
2 & Unidade Produtora de Leitões & Integrado & 5.200 \\
3 & Recria/Terminação & Integrado & 1.250 \\
4 & Recria/Terminação & Integrado & 1.500 \\
5 & Recria/Terminação & Integrado & 650 \\
6 & Recria/Terminação & Integrado & 2.000 \\
7 & Recria/Terminação & Integrado & 1.850 \\
8 & Recria/Terminação & Integrado & 980 \\
9 & Recria/Terminação & Integrado & 1.500 \\
10 & Unidade Produtora de Matrizes & Integrado & 1.000 \\
\hline
\end{tabular}

Fonte: Dados da pesquisa (2017)

\section{Identificação e destinação dos resíduos gerados pela atividade suinícola}

Os sistemas de produção de suínos geram três diferentes tipos de resíduos, sendo assim, classificados:

(a) Efluentes líquidos: dejetos orgânicos formados por fezes, urina, resíduos de ração, água dos bebedouros e de higienização, e outros materiais advindos da criação (KONZEN,1983). 
(b) Resíduos sólidos: dejetos sólidos orgânicos provenientes da limpeza das instalações e resíduos sólidos inorgânicos, como vidros, sacos plásticos, embalagens rígidas plásticas, papel, papelão, lâmpadas, seringas, agulhas, luvas, dentre outros.

(c) Efluentes gasosos: emissões de gás metano gerado pelos dejetos animais, em processo de tratamento aeróbico nas lagoas de estabilização.

Os dejetos líquidos dos suínos contêm matéria orgânica, nitrogênio $(N)$, fósforo $(P)$, potássio $(\mathrm{K})$, cálcio $(\mathrm{Ca})$, sódio $(\mathrm{Na})$, magnésio $(\mathrm{Mg})$, manganês $(\mathrm{Mn})$, ferro $(\mathrm{Fe})$, zinco $(\mathrm{Zn})$, cobre $(\mathrm{Cu})$ e outros elementos incluídos nas dietas dos animais (DIESEL et al., 2002). O armazenado destes dejetos é realizado em esterqueiras impermeabilizadas em geomembrana de Polietileno de Alta Densidade (PEAD), de oito milímetros, e cercadas com tela para evitar a entrada de animais e pessoas.

Os dados apurados apontam que cada unidade produtora de suínos possui dois reservatórios para a armazenagem dos dejetos, com capacidade de retenção hídrica mínima de 120 dias, somada a uma segurança técnica de $20 \%$ em volume. A tabela 2 apresenta a produção de dejetos gerada em cada unidade suinícola e a capacidade de armazenagem dos reservatórios.

Tabela 2 - Produção diária de dejetos e a capacidade das unidades de armazenamento

\begin{tabular}{ccc}
\hline $\begin{array}{c}\text { Unidade de } \\
\text { produção }\end{array}$ & $\begin{array}{c}\text { Produção de dejetos } \\
\text { por dia }\left(\mathbf{m}^{\mathbf{3}}\right)\end{array}$ & $\begin{array}{c}\text { Capacidade das unidades de } \\
\text { armazenamento }\left(\mathbf{m}^{\mathbf{3}}\right)\end{array}$ \\
\hline 1 & 25 & 3.600 \\
2 & 12.5 & 1.800 \\
3 & 2.8 & 600 \\
4 & 3.5 & 520 \\
5 & 1.5 & 220 \\
6 & 4 & 650 \\
7 & 4 & 740 \\
8 & 2 & 300 \\
9 & 3 & 450 \\
10 & 2.5 & 400 \\
\hline Total $\left(\mathbf{m}^{3}\right)$ & 60.8 & 9.280 \\
\hline Fonte: Dados da pesquisa $(2017)$ & \\
\hline
\end{tabular}

A produção de dejetos de suínos nas propriedades pesquisadas, totaliza uma média de 6,08 $\mathrm{m}^{3}$ diários, gerando um volume mensal de $182,4 \mathrm{~m}^{3}$. Os volumes de dejetos podem variar de acordo com a estação do ano. Nos períodos de baixas temperaturas, o volume gerado é menor, pois diminui o consumo de água pelos animais, enquanto que durante o verão, o volume de dejetos aumenta, pois, o consumo de água pelos animais é maior.

Os suinocultores pesquisados planejam a capacidade de acondicionamento, para que seja maior que as recomendações técnicas, a fim de que os dejetos alcancem a estabilização da carga orgânica antes de serem aplicados nas lavouras. Para Seganfredo (2000), as esterqueiras e lagoas, desde que corretamente dimensionadas e operadas, são uma opção de baixo custo para produtores 
que possuem áreas de cultivo suficientes, onde esses resíduos possam ser utilizados como fertilizante orgânico.

No entanto, se verificou a inexistência de esterqueiras com cobertura ou biodigestores nos empreendimentos suinícolas. As esterqueiras cobertas constituem uma importante técnica de produção mais limpa, utilizada na redução dos níveis de patógenos, redução de odores e também evita o transbordamento dos efluentes líquidos em épocas de chuvas intensas.

O uso de biodigestores é uma alternativa tecnológica para o gerenciamento dos dejetos de suínos, e permite a agregação de valor ao resíduo mediante a utilização do biogás produzido em sistemas de geração de energia e calor (PERDOMO et al., 2003). Além disso, os resíduos gerados pela biodigestão podem ser utilizados como biofertilizantes em solos com baixa quantidade de matéria orgânica e também em plantas.

Os resíduos, após o período de estabilização nos sistemas de armazenagem são destinados para a aplicação nas culturas agrícolas de milho e em pastagens forrageiras, conforme descrição apresentada na tabela 3.

Tabela 3 - Quantidade de resíduos de dejetos suínos utilizados como adubação.

\begin{tabular}{|c|c|c|c|}
\hline Culturas & $\begin{array}{l}\text { Média utilizada pe- } \\
\text { los agricultores } \\
\left.\text { pesquisados ( } \mathrm{m}^{3} / \mathrm{ha}\right)\end{array}$ & $\begin{array}{l}\text { Quantidade reco- } \\
\left.\text { mendada ( } \mathrm{m}^{3} / \mathrm{ha}\right)\end{array}$ & Fonte \\
\hline Milho & 10 & 50 & Moraes et al., (2014) \\
\hline Pastagens forrageiras & 12 & 100 & Rosa et al., (2004) \\
\hline
\end{tabular}

As aplicações dos dejetos líquidos nas lavouras variam de $10 \mathrm{~m}^{3}$ por hectare para a cultura do milho e $12 \mathrm{~m}^{3}$ por hectare nas pastagens forrageiras. Ao analisar os dados apresentados pela pesquisa com as fontes de pesquisa utilizadas para a comparação, os volumes de desejos utilizados pelos suinocultores estão abaixo da recomendação técnica.

Porém, Konzen (2004) ressalta que a utilização dos dejetos em culturas agrícolas deve ser adicionada conforme as características do solo e do clima, da exigência das culturas, da declividade do terreno, da época de aplicação, e das formas e equipamentos usados na aplicação.

Segundo Menezes et al., (2007), o uso de dejetos animais como fertilizante pode substituir total ou parcialmente, os adubos minerais comerciais. Além disso, Konzen (1997) enfatiza que a utilização dos dejetos líquidos permite o desenvolvimento de sistemas integrados de produção que diversificam as fontes de renda, promovendo maior estabilidade econômica e social das famílias rurais.

Em contrapartida, nem todos os resíduos gerados pela atividade suinícola podem ser reaproveitados nas unidades de produção. Dessa forma, alguns resíduos precisam ser encaminhados para o tratamento e disposição final, conforme preconiza a legislação ambiental vigente, como é o caso dos resíduos sólidos inorgânicos gerados pela atividade suinícola nas propriedades rurais pesquisadas: vidros, sacos plásticos, embalagens rígidas plásticas, papel, papelão, lâmpadas, seringas, agulhas, luvas, dentre outros. 
Leonhardt (2015) também identificou que a produção de suínos gera outros tipos de resíduos sólidos, sendo estes as embalagens vazias de medicamentos utilizados no processo nas fases de crescimento dos animais, os desinfetantes usados na limpeza e desinfecção das instalações e os perfurocortantes empregados na injeção de medicamentos nos animais.

A quantificação destes materiais não pôde ser realizada, nas propriedades rurais pesquisadas devido à inexistência de locais adequados para a armazenagem, sendo que os mesmos eram despejados em valas e cobertos com terra, ou até mesmo incinerados.

Sobre a quantificação dos resíduos em sistemas de produção de suínos, uma pesquisa realizada por Leonhardt (2015) constatou a geração de um montante de $867,56 \mathrm{Kg}$ em um ano, sendo $88,55 \%$ desse volume total representados por embalagens plásticas, $11,35 \%$ pelas por embalagens de vidro, e $0,53 \%$ por materiais perfuro-cortantes.

Salienta-se que estes resíduos contêm substâncias perigosas, não sendo recomendado que sejam enterrados, pois estes podem contaminar as águas subterrâneas e/ou o solo. Nessas situações, ressalta-se a responsabilidade das empresas ou cooperativas agroprocessadoras em recolher estes resíduos e encaminhar os mesmos para a reciclagem ou para o tratamento adequado, para posterior disposição final.

Segundo NBR no 12807 (ASSOCIAÇÃO BRASILEIRA DE NORMAS TÉCNICAS, 1993) todo material gerado durante uma prestação de serviço de assistência média, odontológica, laboratorial e instituições de ensino e pesquisa médica, relacionados à população humana e/ou animal é considerado Resíduo de Serviços de Saúde (RSS). Assim, as propriedades rurais suinícolas geram este tipo de resíduo (perfuro-cortantes), e se enquadram no Grupo E, conforme a resolução do Conama no 358/2005, e por isso estes materiais utilizados nas propriedades devem ser tratados previamente para eliminação de riscos biológicos, e posteriormente encaminhados para aterro de resíduos perigosos - Classe I (CONSELHO NACIONAL DO MEIO AMBIENTE, 2005).

Com relação aos resíduos domiciliares, Darolt (2008) enfatiza que a correta destinação dos resíduos passa pela coleta seletiva e pelo recolhimento por transporte específico, levando os mesmos para aterros sanitários ou para reciclagem.

A atividade suinícola também gera resíduos sólidos que envolvem as carcaças dos animais mortos durante as fases de produção e os restos placentários, que devem ser encaminhados para um sistema de compostagem (FRANQUETO et al., 2016).

Em relação ao destino dado aos animais mortos e restos placentários da atividade suinícola, as propriedades rurais realizam a compostagem desses resíduos, e os aplicam como adubo orgânico em pomares ou em cultivos agrícolas.

De acordo com Bueno et al., (2008), a compostagem é um método natural e econômico de reciclagem da matéria orgânica, definida pela decomposição e estabilização biológica de substratos orgânicos, sob condições que permitam o desenvolvimento de temperaturas como resultado do calor biológico produzido, para obtenção de um composto final estável, livre de patógenos e que pode ser aplicado como fertilizante no solo. 
Uma das formas para minimizar os efeitos dos efluentes gasosos é a implantação de biodigestores, que podem contribuir na geração de biofertilizante e biogás. Porém, foi verificado que as unidades de produção suinícolas não dispõem de biodigestores para minimizar os efeitos dos efluentes gasosos.

Os efluentes gasosos gerados pela atividade suinícola podem ser identificados pelos gases, vapores e poeiras, que podem comprometer o conforto e a saúde de homens e animais, além de corroer equipamentos e edificações.

Lovatto (1996) salienta que os gases produzidos pela concentração desses dejetos, são a amônia $\left(\mathrm{NH}_{4}\right)$, sulfeto de hidrogênio $\left(\mathrm{H}_{2} \mathrm{~S}\right)$, dióxido de carbono $\left(\mathrm{CO}_{2}\right)$, metano $\left(\mathrm{CH}_{4}\right)$ e odores ruins que são produzidos pelos próprios gases e também por compostos orgânicos que resultam de decomposição biológica da matéria orgânica.

Uma das formas para minimizar os efeitos dos efluentes gasosos é a implantação de biodigestores. Estes equipamentos são herméticos e impermeáveis dentro dos quais se deposita material orgânico para fermentar por um determinado tempo de retenção, no qual ocorre um processo bioquímico denominado biodigestão anaeróbica, que tem como resultado a formação de biofertilizante e biogás (MAGALHÃES, 1986).

O biogás produzido fica retido na parte livre do biodigestor, que pode ser canalizado para ser utilizado em aplicações diversas, como processos de aquecimento e resfriamento e na geração de energia elétrica. E o biofertilizante como já foi enfatizado pode ser utilizando nos cultivos agrícolas.

Porém, foi verificado que as unidades de produção suinícolas não dispõem de biodigestores para minimizar os efeitos dos efluentes gasosos, pois esta é ainda uma tecnologia com um alto valor de implantação, e na região sul são identificados problemas de operacionalização, devido às baixas temperaturas registradas, o que diminui a eficiência destes equipamentos.

Por fim, destaca-se que a gestão correta dos resíduos gerados pela atividade suinícola pode representar um diferencial na cadeia produtiva, além de manter o equilíbrio entre o processo produtivo e o meio ambiente. Para efetivação das práticas de gestão, é necessária a participação de todos os agentes envolvidos diretamente e indiretamente no processo produtivo, entre eles os produtores, as empresas fornecedoras de insumos, de assistência técnica, órgãos regulamentadores, entre outros. A difusão de novas tecnologias, conhecimento, técnicas e metodologias podem contribuir para uma maior eficiência no manejo, armazenamento, tratamento e disposição final destes resíduos, trazendo benefícios para os suinocultores, e principalmente, para o meio ambiente. 


\section{Considerações Finais}

Ao finalizar este trabalho, verificou-se que um dos principais sistemas de produção adotado pelos produtores pesquisados é o sistema de recria-terminação, realizado de modo confinado desenvolvida de forma integrada com as agroindústrias.

Com relação aos resíduos gerados nas propriedades rurais, constatou-se que são produzidos efluentes líquidos, efluentes gasosos e resíduos sólidos. Os dejetos orgânicos líquidos da suinocultura são armazenados em esterqueiras, e posteriormente são aplicados nos cultivos de milho e pastagens forrageiras. Um dos pontos limitantes identificados se refere à inexistência de esterqueiras cobertas ou biodigestores para o adequado tratamento dos dejetos.

Os resíduos sólidos inorgânicos gerados pela atividade suinícola são: vidros, sacos plásticos, embalagens rígidas plásticas, papel, papelão, lâmpadas, seringas, agulhas, luvas, dentre outros, porém, a quantificação destes materiais não pode ser realizada, pois nas propriedades rurais pesquisadas, inexistiam locais adequados para a armazenagem.

Em relação ao destino dado aos animais mortos e restos placentários da atividade suinícola, as propriedades rurais realizam a compostagem desses resíduos, e os aplicam como adubo orgânico em pomares ou em cultivos agrícolas.

Quanto aos efluentes gasosos foi verificado que as unidades de produção suinícolas não dispõem de biodigestores para minimizar os efeitos poluidores destes.

Por fim, destaca-se que a gestão correta dos resíduos gerados pela atividade suinícola pode representar um diferencial na cadeia produtiva, além de manter o equilíbrio entre o processo produtivo e o ambiente. Para efetivação das práticas de gestão, é necessária a participação de todos os agentes envolvidos diretamente e indiretamente no processo produtivo, entre eles os produtores, as fornecedoras de insumos, as agroprocessadoras, a assistência técnica, órgãos regulamentadores, prefeituras municipais, entre outros. A difusão de novas tecnologias, conhecimento, técnicas e metodologias podem contribuir para uma maior eficiência no manejo, armazenamento, tratamento e disposição final destes resíduos, trazendo benefícios para os suinocultores, e principalmente, para o meio ambiente.

Desse modo, os dados apresentados pela pesquisa, demostram a importância econômica e social da atividade suinícola para o município de Palmitinho e a Região Noroeste do RS e, diante disto cabe salientar a imprescindibilidade da correta adequação ambiental das unidades produtoras bem como a sensibilização dos criadores a respeito da responsabilidade ambiental e social que seus empreendimentos possuem. 


\section{Referências}

ASSOCIAÇÃO BRASILEIRA DE NORMAS TÉCNICAS - ABNT. NBR 12807: Resíduos de Serviços de Saúde. Rio Janeiro: ABNT, 1993. Disponível em: <http://licenciadorambiental.com.br/wpcontent/uploads/2015/01/NBR-12.807-Residuos-de-Servi\%C3\%A7os-de-sa\%C3\%BAde.pdf>. Acesso em: 23 jan. 2018.

ASSOCIAÇÃO DOS SUINOCULTORES DO ESTADO DO RIO GRANDE DO SUL - ACSURS. Produção de Suínos no Rio Grande do Sul. 2017

BARICHELLO, R. et al. O uso de biodigestores em pequenas e médias propriedades rurais com ênfase na agregação de valor: um estudo de caso na região noroeste do Rio grande do sul. Revista em Agronegócio e Meio Ambiente, v. 8, n. 2, p.333-355, mai./ago. 2015. Disponível em: <http://dx.doi.org/10.17765/2176-9168.2015v8n2p333-355>. Acesso em: 08 mar 2018.

BELI, E.; HUSSAR, G. J.; HUSSAR, D. H. Redução de DQO e turbidez de efluente de uma unidade suinícola empregando reator anaeróbio compartimentado (RAC) seguido de filtro biológico e filtro de areia. Engenharia Ambiental, Espírito Santo do Pinhal, v. 7, n. 1, p. 005-019, jan./mar. 2010.

BERTÊ, A. et al. Perfil Socioeconômico - Corede Médio Alto Uruguai. In: Boletim Geográfico Do Rio Grande Do Sul, Porto Alegre, v. 26, p. 442-477, 2016.

BERTOL, O.J. et al. Mobilidade de P, Cu e $\mathrm{Zn}$ em colunas de solo sob sistema de semeadura direta submetido às adubações mineral e orgânica. Revista Brasileira de Ciência do Solo, v. 34, p. 18411850, 2010.

INSTITUTO BRASILEIRO DE GEOGRAFIA E ESTATÍSTICA - IBGE. Estatísticas do Censo Agropecuário. 2006a. Disponível em: https://www.ibge.gov.br/estatisticasnovoportal/economicas/agricultura-e-pecuaria/9827-censo-

agropecuario.html?edicao=9830\&t=destaques. Acesso em: 08 mar 2018.

L. Informações por município. 2006b. Disponível em:

https://cidades.ibge.gov.br/brasil/rs/palmitinho/pesquisa/24/27745. Acesso em: 08 mar 2018.

BUENO, P. et al. Optimizing Composting Parameters For Nitrogen Conservation In Composting. Bioresource Technology, v.11, p. 5069-5077, 2008.

CAMPOS, G. et al. A produção mais limpa na suinocultura do distrito federal. Dissertação de Mestrado do Programa de Pós-graduação Agronegócios, da Faculdade de Agronomia e Medicina Veterinária da Universidade de Brasília (UnB). Brasília- DF. 2014.

CARDOSO, B. F.; OYAMADA, G. C.; SILVA, C. M. da. Produção, tratamento e uso dos dejetos suínos no Brasil. Desenvolvimento em Questão, v. 13, n. 32, p. 127-145, 2015. Disponível em: $<$ https://www.revistas.unijui.edu.br/index.php/desenvolvimentoemquestao/article/view/3159>. Acesso em: 23 jan. 2018.

CONSELHO NACIONAL DO MEIO AMBIENTE - CONAMA. Resolução no 358: resíduos sólidos oriundos do serviço de saúde. 2005. Disponível em: <http://www.mma.gov.br/port/conama/res/res05/res35805.pdf>. Acesso em: 22 jan. 2018.

DAROLT, M. R. Lixo rural: do problema à solução. 2008. Disponível em: <http://www.comciencia.br/comciencia/?section=8\&edicao=32\&id=373>. Acesso em: 7 Jul. 2017.

DIESEL, R.; MIRANDA, R. C.; PERDOMO, C. C.; Coletânea de tecnologias sobre dejetos suínos. Boletim Informativo de Pesquisa-Embrapa Suínos e Aves e Extensão-EMATER/RS, Articulação da Embrapa Suínos e Aves com a Associação Rio-grandense de Empreendimentos de Assistência Técnica e Extensão Rural - EMATER/RS, 2002. 
FRANQUETO, R. et al. Destinação de carcaças de animais mortos provenientes de suinocultura em granja no Estado do Paraná. Revista Tecnologia e Ambiente, v. 18, p. 31-43, 2016. Disponível em: <http://periodicos.unesc.net/tecnoambiente/article/view/2959> Acesso em: 23 jan. 2018.

KONZEN, E. A. Manejo e utilização de dejetos suínos. Concórdia: EMBRAPA-CNPSA, 1983.

. Valorização agronômica dos dejetos suínos: utilização dos dejetos suínos como fertilizantes. In: CICLO DE PALESTRAS SOBRE DEJETOS SUÍNOS NO SUDOESTE GOIANO, 1., 1997, Rio Verde. Anais... Rio Verde, 1997. p. 113-136.

Fertilização de lavoura e pastagens com dejetos de suínos e cama de aves. Embrapa Milho e Sorgo, Sete Lagoas, 2004. p. 1-10.

LEONHARDT, R. B. Avaliação da destinação final dos resíduos sólidos de serviços de saúde veterinários em integradora de suínos. 2015. 74 f. Monografia (Graduação) - Curso de Engenharia Ambiental, Centro Universitário Univates, Lajeado, 2015. Disponível em: $<$ https://www.univates.br/bdu/bitstream/10737/947/1/2015RodrigoBuchnerLeonhardt.pdf>. Acesso em: 22 jan. 2018.

LOVATTO, P. Suinocultura Geral. Santa Maria, 1996.

MAGALHÃES, A.P. T. Biogás: um projeto de saneamento urbano. São Paulo: Nobel, 1986.

MENEZES, J.F.S. et al. Aproveitamento de dejetos de suínos na produção agrícola e monitoramento do impacto ambiental. Goiás: Universidade de Rio Verde, 2007.

MORAES, M. T. et al. Dejetos líquidos de suínos como alternativa a adubação mineral na cultura do milho. Semina: Ciências Agrarias, v. 35, n. 6, p. 2945-2954, 2014.

PERDOMO, C. C.; OLIVEIRA, P. A. V.; KUNZ, A. Sistemas de tratamento de dejetos suínos: inventário tecnológico. Concórdia: Embrapa Suínos e Aves, 2003.

ROSA, B.; NAVES, M.A.T.; RAMOS, C.S. Utilização de dejetos líquidos de suínos na produção e composição quimico-bromatolólogica do capim Braquiarão" Brachiaria brizantha cv.marandu". In: REUNIÃO ANUAL DA SOCIEDADE BRASILEIRA DE ZOOTECNIA, 40, 2004, Campo Grande. Anais... Campo Grande: Sociedade Brasileira de Zootecnia, 2004.

SEGANFREDO, M. A. A questão ambiental na utilização de dejetos de suínos como fertilizante do solo. Circular Técnica, Concórdia: Embrapa, n. 22, 2000.

SOBESTIANSKY, J. et al. Suinocultura Intensiva. Brasília: Serviço de Produção de Informação SPI, 1998.

VIELMO, $\mathrm{H}$. et al. Effect of fertilization with fluid swine slurry on production and nutritive value of Tifton 85. Revista Brasileira de Zootecnia, v. 40, p. 60-68, 2011. 


\section{Apêndice A - Roteiro de perguntas utilizadas para a coleta das in- formações}

Propriedade rural

\section{Sistemas de produção desenvolvidos na propriedade rural:}

( ) Suínos - quantidade de animais:

Tipo de produção: ( ) UPL 21 dias ( ) Ciclo completo ( ) Terminação

Área Total da propriedade rural:

( ) Leite - quantidade de animais:

( ) Milho - quantidade de hectares:

( ) Trigo - quantidade de hectares:

( ) Soja - quantidade de hectares:

( ) Outra

2. O empreendimento (sistema de produção de suínos) possui licenciamento ambiental?

( ) Sim ( ) Não

O Órgão Licenciador é: ( ) FEPAN ( ) Município

\section{Qual é o sistema de tratamento de dejetos existentes no empreendimento?}

( ) Lagoas dimensionadas com cobertura ( ) Lagoas dimensionadas sem cobertura

( ) Biodigestor ( ) Leito de secagem

Quantidade de lagoas:

Qual é o tamanho:

Capacidade total de acondicionamento:

Os dejetos permanecem nas lagoas quantos dias ou meses:

3.1 Em quais culturas são colocadas os dejetos orgânicos de suínos?

3.2 Qual é quantidade de dejetos suínos que são adicionados por hectare nas culturas existentes na propriedade rural?

3.3 Qual é a periodicidade da aplicação destes dejetos orgânicos de suínos nas culturas existentes na propriedade rural?

\section{Quais são os outros resíduos gerados pela atividade produtiva?}

( ) Plásticos

- Destino adotado:

( )Embalagens de medicamentos-Vidros- Destino adotado:
( ) Papel-Papelão
- Destino adotado:
( ) Lâmpadas
- Destino adotado: 
( ) Seringas, agulhas

( ) Luvas

( ) Outros
- Destino adotado:

- Destino adotado:

- Destino adotado:

5. Os animais mortos durante a fase de criação, qual é a destinação adotada para este resíduo?

Descrever o destino adotado:

6. Os resíduos domiciliares sólidos (plásticos, papéis, vidros...) - qual é o destino adotado? Descrever o destino adotado:

7. Os resíduos domiciliares orgânicos (cascas, restos de alimentos...) - qual é o destino adotado?

Descrever o destino adotado: 